\title{
Sustainability views of adaptation measures due to climate change in agriculture in two AEZs, Bangladesh
}

\author{
Rezaul Karim ${ }^{1}$ \\ ${ }^{1}$ (Department of Environmental Science and Technology, Jessore University of Science and Technology, \\ Jessore-7408, Bangladesh)
}

\begin{abstract}
Different physiological part of Bangladesh have different socio-economical potential but are at the same time vulnerable to destructive effects of climate change differently in various sectors like agriculture, human settlements, health, ecosystem and security. Autonomous adaptation measures used by local communities against natural hazards in two agro-ecological zones of Bangladesh have been gathered and evaluated using a rated set of eleven criteria which has been derived from principles of sustainable adaptation. As a result of this study several adaptation measures showed high sustainability, some medium but most of them with a low sustainability in terms of effectiveness, efficiency and implementation ability. To enhance local adaptive capacity in terms of its hazard context and to modify adaptation measures it is necessary to give priorities to sectors which are more vulnerable and also potential for national economic activities.
\end{abstract}

Keywords: Impacts of climate change, Climate change adaptation and Sustainable adaptation.

\section{Introduction}

Bangladesh is one of the most climate vulnerable countries in the world due to its hydro-geological and socio-economic factors. Bangladesh, especially its coastal zones, experiences natural hazards like flooding, water logging, tropical cyclone, storm surges, droughts and coastal erosions, nearly every year [1]. By living together with the frequent natural hazards, people and society system of Bangladesh have high level of knowledge and experience to coping effects locally in some degree and extent. But frequent and severe conducting natural hazards make people more vulnerable to do something in the great extent of disaster due to climate change.

All over Bangladesh, different adaptation practices including technological measures, behavioural approach, managerial advances and policy are carried out. Technological measures are constructed embankment, bridge, sluice gate to control flood and river erosion; cyclone centre, coastal embankment for cyclone and storm surges; and irrigation method for drought. There are some managerial advances which are proved very effective for facing climate change impacts. In the coastal zone, most of them are adopted as community based adaptation from this region. These adaptation measures include: floating gardens for cropping and vegetables, community based rich-fish farm in the low lands; cultivation of saline resistant varieties of rice and other crops to improve productivity and nutritional security [2].

Adaptation must fulfil the criteria to gain sustainable development and also must be evaluated based on mainly effectiveness in risk reducing, economic feasibility and social acceptance [3]. The aim of this research was to analyze the sustainability views of adaptation measures to the potential impacts due to climate change in the two natural hazards prone zone of Bangladesh. Specific objectives were to find out adaptation measures in affected socio-economic sectors in the study area, to develop the principles of sustainable adaptation in context of climate change and criteria for evaluation of measures and finally, to analyze the adaptation measures in the study area in the socio-economic sectors.

\section{Material and Methods}

Study area

There were selected two Agro-ecological Zones (AEZ - 7 and AEZ-11) for the study which are vulnerable to climate change (Figure 1). Geographically and geo-morphologically, these regions are the prone areas of natural disasters. These regions are characterized by crisscrossed networks of rivers and discharging huge sediments by rivers. The potential impacts of natural hazards are being enhanced by the geo-physical conditions including northwardly islands in between the channels and rivers; a very shallow area all along the coast, particularly in the central region, and also a submarine canyon in the western region [4,5]. Due to climate change, this zone is becoming more vulnerable than other part of the country. 


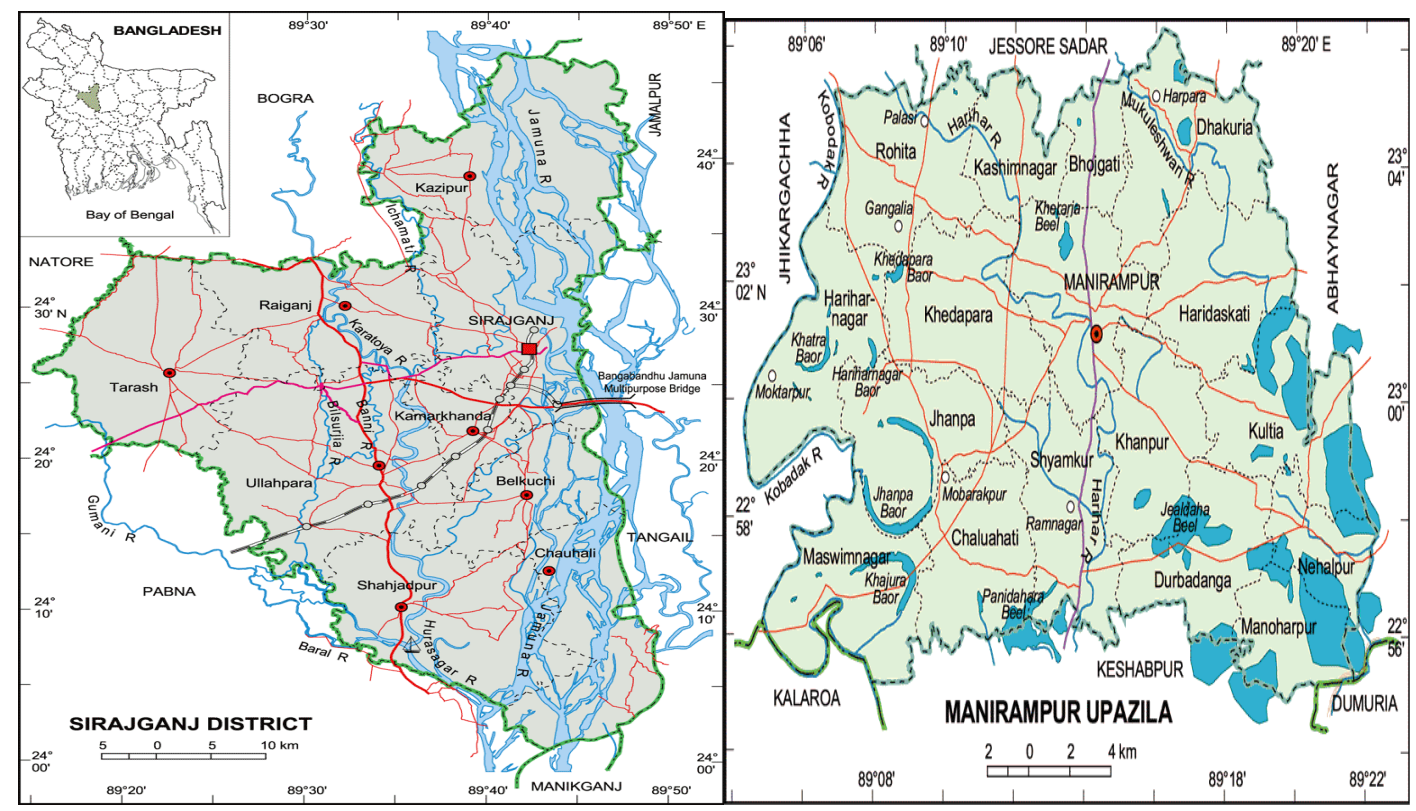

Figure I (a) Map of Chaohali, Sirajgonj

b) Manirampur, Jessore

On the context of Agro-ecological zoning (which are based on hydrology, physiography, soil types, tidal activity, cropping patterns, and seasons), there are thirty AEZ's in Bangladesh. The study area covered the interior coastal areas the Ganges flood plain (AEZ 11) [6] and Active Brahmaputra-Jamuna Floodplain (AEZ 7) [7] (Table II-I).

Table II-I: Study area covered AEZs

\begin{tabular}{|l|l|l|}
\hline AEZ & \multicolumn{1}{|c|}{ Region } & Corresponding Study area / village \\
\hline AEZ- 7 & Active Brahmaputra-Jamuna Floodplain & Voalkandi and Estholchore \\
\hline AEZ-11 & Interior Coast & Bhojgati and Manirampur \\
\hline
\end{tabular}

AEZ 11 is predominantly highland and medium highland. Lower parts of ridges and basin margins are seasonally shallowly flooded [7]. General soil types predominantly include calcareous dark grey floodplain soils and calcareous brown floodplain soils. General fertility level is low. Organic matter content in the brown ridge soils is low but higher in the dark grey soils. Soils are slightly alkaline in reaction [8]. The average rainfall is about $1537 \mathrm{~mm}$. The annual average temperatures are Maximum $37.1^{\circ} \mathrm{C}$, minimum $11.2^{\circ} \mathrm{C}$ [9]. On the otherhand, Chauhali upazila, Sirajgonj, Bangladesh (is located on the bank of Jamuna River. The region was affected by soil erosion and flooding and frequent food shortage due to uncertainty of rainfall. Therefore, the region is susceptible to climate change and the ultimate effect goes on agriculture production [10].

Methods

The study was conducted in the context of the climatic facts of two vulnerable regions of Bangladesh. The states of the art of the problems are discussed on the basis of questionnaire survey. Mainly Personal Interviews among the villagers in the study were followed to fulfill the required field research work of the thesis. There were interviewed 25 participants in each village of the two study areas. There were 25 set of reports from two villages each study area. These were segregated and compiled. Tables and bar charts were used to present different variables. Cross-tabulation allowed a comparison of different study parameters in the two study areas.

To analyze the adaptation measures in the two zones, there have been developed principles of sustainable adaptation. It was found that the dynamic contexts on social, economical, technological, biophysical and political should be considered in climate change adaptation but these contexts vary over time, location, and sector [3]. The process of enhancing adaptive capacity interprets a practical means of coping with changes and uncertainties in climate. In this way, enhancement of adaptive capacity reduces vulnerabilities and promotes sustainable development [3]. These principles are Social principles of sustainable adaptation (Promoting basic need for people e.g. food security, safe water and health care, shelter and access to other resources and education; Participating local people and accumulating their experience and Incorporating cultural diversity in adaptation), Economic principles of sustainable adaptation (Accounting cost in adaptation), Biophysical principles of sustainable adaptation (Improving access to local resources, Improving infrastructure and Improving institutional capacity and efficiency) and Technical principles of sustainable adaptation (Assuring technical support). On the basis of the above principals of sustainable adaptation, it is developed a set of criteria 
for analyzing the sustainability views of adaptation measures (Table 2). In ranking, the participate give their perception valued as 1, 2 and 3 for High, Medium and Low sustainability. The final evaluation was calculated as 25- 33 as High sustainable, 18-24 Medium sustainable and below 18 low sustainable.

Table II-II: Evaluation criteria and rating in scale

\begin{tabular}{|c|l|l|}
\hline & Evaluation Criteria & Scale \\
\hline 1. & Effectiveness for potential mitigation & High (H) \\
\hline 2. & Implement ability for the present need & Medium (M) \\
Low (L) & \\
\hline 3. & Feasibility & \\
\hline 5. & Relevance to vulnerable community & \\
\hline 6. & Suitability for future climate scenarios & \\
\hline 7. & Epplicability to multiple events & \\
\hline 8. & Local people Participation & \\
\hline 1. & Environmental friendliness & \\
\hline 1. & Ecosystem connectivity & \\
\hline
\end{tabular}

\section{Result and discussion}

Interior coast and the flood plain are facing different types of hazards and affected in different way on the socio-economic sectors of the zones. People also gather different experiences and also adopt in different ways in the agriculture, human settlement and their own security.

\section{Main Problems enhanced by Climate Changes}

In the interior coast, there are been noticed a number of climatic hazards including flooding and water logging, river erosion, storm and tidal surge. Flooding is the most one due to siltation in the river and also unplanned road networks. The frequency of flood has decreased but the intensity increased in a significant manner. Water logging is due to sedimentation of the rivers and canals and also unplanned sluice gate. River erosion is also most responsible for loss of human settlement. In some part of this zone, drought is also privileged. Frequency, magnitude, timing of occurrence and ranking of natural hazards in interior coast are given in Table 3.

Due to changes in climatic variables like rainfall pattern change and increased temperature and humidity, there are also observed heavy rain fall and heavy fog. Other problems associated to climate change are severe rats and pests attack in agricultural fields. Arsenic in drinking is also another problem in the interior coast due to accelerating huge amount of ground water for agriculture and domestic uses.

Table III-I: Frequency, magnitude, timing of occurrence and ranking of natural hazards in interior coast

\begin{tabular}{|c|c|c|c|c|}
\hline Events & Frequency & Magnitude & Timing of occurrence & Rank \\
\hline Cyclone and storm surge & ++ & +++ & ++ & 3 \\
\hline Saline water intrusion & +++ & ++ & +++ & 2 \\
\hline Flooding and water logging & +++ & +++ & +++ & 1 \\
\hline Drainage congestion & ++ & + & ++ & 4 \\
\hline Erosion & + & + & + & 5 \\
\hline Drought & - & - & - & 7 \\
\hline Others: heavy fog, attack rat & + & + & + & 6 \\
\hline
\end{tabular}

In the flood plain, there are also found that the regions are facing climate change in different way due to difference in its hydrology and morphology. Flooding and river bank erosion are the main hazards which are being increasing with its magnitude and frequency. There are also little drought in these areas. No Salinity intrusion is being exposed. Frequency, magnitude, timing of occurrence and ranking of natural hazards in flood plain regions are given in Table III-II.

Table III-II: Frequency, magnitude, timing of occurrence and ranking of natural hazards in exposed coast

\begin{tabular}{|l|c|c|c|c|}
\hline Events & Frequency & Magnitude & Timing of occurrence & Rank \\
\hline Cyclone and storm surge & + & + & + & + \\
\hline Saline water intrusion & + & + & + & ++ \\
\hline Flooding and water logging & +++ & ++ & + & + \\
\hline Drainage congestion & + & + & +++ & + \\
\hline Erosion & +++ & ++ & + & + \\
\hline Drought & ++ & + & + & + \\
\hline Others: heavy fog, attack rat & + & + & + \\
\hline
\end{tabular}




\section{Effected Socio economic sectors}

In the interior coast, agriculture and human settlement are most affected by flooding and river erosion (Table III-III). In the interior coast, there are also caused low soil productivity and increase pest problem. Wheat production is disturbed due to this change. In addition, Heavy fog (decreasing the production of wheat, mustard, etc) and attack of rats and pests in the crop fields are also blamed to human security in lack of crop production. In the exposed coast, saline water encroaches by shrimp farmer and the shrimp farming land become out-ofcultivation (Table III-IV).

Table III-III: Intensity of impacts on different sectors in the interior coast

\begin{tabular}{|c|c|c|c|c|c|c|c|}
\hline \multirow{2}{*}{$\begin{array}{l}\text { Socio economic } \\
\text { Sectors }\end{array}$} & \multicolumn{7}{|c|}{ Events } \\
\hline & Cyclone & $\begin{array}{l}\text { Saline water } \\
\text { intrusion }\end{array}$ & Flooding & $\begin{array}{l}\text { Drainage } \\
\text { congestion }\end{array}$ & Erosion & Drought & $\begin{array}{l}\text { insects } \\
\text { attack }\end{array}$ \\
\hline Agriculture & +++ & +++ & ++ & + & - & ++ & + \\
\hline Human settlement & +++ & - & ++ & + & - & - & \\
\hline Ecosystem & +++ & +++ & ++ & - & - & ++ & + \\
\hline
\end{tabular}

Table III-IV: Intensity of impacts on different sectors in the flood plain

\begin{tabular}{|c|c|c|c|c|c|c|c|}
\hline \multirow[b]{2}{*}{$\begin{array}{l}\text { Socio economic } \\
\text { Sectors }\end{array}$} & \multicolumn{7}{|c|}{ Events } \\
\hline & $\begin{array}{l}\text { Cyclone } \\
\text { storm surge }\end{array}$ & $\begin{array}{l}\text { Saline } \\
\text { intrusion }\end{array}$ & Flooding & $\begin{array}{l}\text { Drainage } \\
\text { congestion }\end{array}$ & Erosion & Drought & $\begin{array}{l}\text { Other } \\
\text { Insects } \\
\text { attack }\end{array}$ \\
\hline Health & + & - & +++ & + & +++ & ++ & \\
\hline $\begin{array}{l}\text { Human } \\
\text { settlement }\end{array}$ & + & - & +++ & + & +++ & - & \\
\hline
\end{tabular}

\section{Adaptation measures in Agriculture}

Local adaptation measures taken importantly in agriculture and livelihood in the interior coasts and flood plain regions are discussed commonly below:

Crop diversification: In this region, there are introduced the change in cropping pattern. The people introduced new crop in their flood or drought affected area. The new crops are maize, high yielding variety rice, some commercial crop, etc. Corn cultivation during drought, Instead of Aman, Aus, Jute, IRRI 28, 29, Mustard, Potato, Onion, Sugar cane, Wheat, Vegetables etc. In low rainfall people are supplying water in their paddy field from nearby canals and rivers by pumps. Alternative crop cultivations are practiced i.e. IRRI instead of Aus.

Floating Agriculture: Traditionally some communities in the coastal zone, there have been used hydroponics to use as land for some sort of agriculture. This local adaptation measures has been introducing in to other wetland areas.

Seed preservation: The seed with good quality are preserved for the next season. In this process, farmers select the best quality seed; dry under the sun light and put it into the jar with earthen plate and finally the jar is sealed with clay.

Integrated firming: In the water logged/ low land area, fish, rice, vegetables and poultry simultaneous are cultivated as integrated firming.

The 'Kandi-paya Ber' cultivation: In this method, the land is artificially undulated. Farmer creates successive high and low structure made of soil. In the higher part, they cultivate banana, tomato etc.

Plantation of hazards tolerant trees: People plant hazard tolerant trees e.g. coconuts and plants around their houses and homesteads to protect them from flood impacts and erosion and also deep rooted tress that protect from violent wind speed by cyclone.

Fish preservation: For domestic demand, they often cultivate fish in small pond. For business purpose before marketing, local fisherman preserve fish up to 2 to 3 days in a shallow hole beside tube well.

Shrimp culture: Shrimp culture increased significantly in the previous years where rice fields are degraded due to salinity intrusion.

\section{Sustainability views}

The criteria adopted from the principles of sustainable adaptation are numbered as 1 to 11 and then the measures gathered from the field survey for agriculture, human settlement, security and others were evaluated using the scale: high, medium and low. From the field survey analysis and in some cases own views are used to evaluate these measures. Sustainability of adaptation in agriculture is analyzed in Table III-V. 
Sustainability views of adaptation measures due to climate change in agriculture in two AEZs,

Table III-V: Sustainability of adaptation measures in agriculture

\begin{tabular}{|l|l|l|l|l|l|l|l|l|l|l|l|l|l|}
\hline No & Adaptation measures & 1 & 2 & 3 & 4 & 5 & 6 & 7 & 8 & 9 & 10 & 11 & $\begin{array}{l}\text { Overall } \\
\text { sustainability }\end{array}$ \\
\hline 1 & Crop diversification & H & H & M & H & H & M & H & H & M & H & M & High \\
\hline 2 & Floating Agriculture & M & M & H & H & M & L & H & L & H & M & M & Medium \\
\hline 3 & Seed preservation & L & M & H & L & H & H & H & L & M & M & M & Medium \\
\hline 4 & Integrated firming & H & H & M & M & H & M & H & H & H & M & M & High \\
\hline 5 & Planting tree & M & H & M & M & M & M & H & M & H & M & M & Medium \\
\hline 6 & Fish preservation & M & M & H & M & M & L & H & M & M & L & M & Medium \\
\hline 7 & Kandi paya ber & M & H & M & M & M & L & H & M & H & L & M & Medium \\
\hline 8 & Shrimp culture & L & H & L & L & H & L & H & H & L & L & H & Medium \\
\hline
\end{tabular}

\section{Conclusion}

People of the both zones have been suffering from climatic events for long time and they are trying to adjust with changing climate through different coping mechanisms. It is evidence that climate change varies among the AEZs and the impacts also varies in the interior and exposed coasts. Therefore, the coping mechanisms are also observed different in the two AEZs.

There is being diversified crops in agriculture practices. These showed high sustainability in criteria of effectiveness, implement ability, relevance, suitability and economic value. They showed medium sustainability due to four criteria: low feasibility, not applicable for multiple events and friendliness high to relevant environment, low to another environmental and low social acceptance. Others measures were: integrating farming, shrimp culture are medium to high sustainable in terms of present need, single applicability, economic viability but low sustainable in terms of local participation and multiple sector applicability.

In Bangladesh, while working with climate change and its impacts and adaptation, it is also necessary to consider the type of AEZ (interior coast or flood plain land). It is necessary to enhance local adaptive capacity in terms of its hazards context and to give priorities to these which are more vulnerable and also potential for national economic activities.

\section{References}

[1] Ahmed, A. U., Bangladesh: Climate Change Impacts and Vulnerability - a Synthesis, (Dhaka: GoB, MoEF, Department of Environment, Climate Change Cell, July); Available at: http://www.climatechangecell-bd.org/publications/06ccimpactvulnerability. Pdf. (Accessed 12 February 2009

[2] Rahman, S.H., Alam, A.K.M.R., Saadat, A.H.M. and Uddin, M.J., Climate Change Adaptation Practices in Thirty Agro-ecological Zones of Bangladesh, (unpublished project report submitted to OXFAM international, Bangladesh) 2009

[3] Intergovernmental Panel on Climate Change (IPCC), 3rd Assessment Report: impacts, adaptation and vulnerability. Working Group II, Available at: http://www. grida.no/climate/ipcc/tar/wg2 /pdf/wg2 TARchap18.pdf (Accesses on 10 March, 2009)

[4] Ali, A., Climate change impacts and adaptation assessment in Bangladesh. Climate Research, 1999, 12 (2/3). 109-116

[5] Ali, A., Vulnerability of Bangladesh Coastal Region to Climate Change with Adaptation Options (Dhaka: Bangladesh Space Research and Remote Sensing Organization (SPARRSO)); available at: http://www.survas.mdx.ac.uk/pdfs/3anwaral.pdf (Accessed 28 January 2009).

[6] Sarwar, G.M., Impacts of sea level rise on the coastal zone of Bangladesh. Master's dissertation, Lund University, Sweden, 2005.

[7] Brammer, H., The Agroecology of Bangladesh's Floodplains, (unknown publisher) 1987

[8] Banglapedia, Agroecological zone, Asiatic Society, Dhaka, Bangladesh, 2011

[9] Jessorebazar, Jessore, available at: http://www.jessorebazar.com/jessore-district-information-for-you.html; (Accessed on 12 Nov 2012)

[10] Banglapedia, Drought. Asiatic Society, Dhaka, Bangladesh, 2010 